\title{
Palabra, silencio e igualdad de las inteligencias. Pensar la praxis docente desde un realismo-pragmático salvaje
}

JUAN DIEGO GARCÍA ${ }^{(1)}$

Fecha de recepción: 17/02/2020

Fecha de aceptación: 03/07/2020

Resumen. En el presente ensayo proponemos detenernos en torno a un problema recurrente en la praxis docente: la falta de circulación de la palabra en el aula, muchas veces acompañada del desinterés y la apatía de los estudiantes en relación con la propuesta didáctica. Para pensarlo proponemos partir de un relato de experiencia propio, donde este problema se hace presente, y luego esbozaremos una perspectiva de análisis de la praxis docente, que denominaremos «realismo-pragmático salvaje». La misma nos va a permitir pensar e interrogar el relato de experiencia de un modo singular. Por último, pondremos en relación esta perspectiva con algunas categorías de El maestro ignorante de Jaques Rancière, para intentar problematizar la cuestión del habla y el silencio en las clases.

Palabras clave. Rancière $\cdot$ habla $\cdot$ igualdad . impotencia-potencia.
(1) Universidad Católica de Santa Fe (UCSF). Profesor de Filosofía por la Universidad Nacional del Litoral (UNL). Dicta clases en distintas escuelas secundarias y en la UCSF. Investiga y trabaja temas y problemas relacionados al pensamiento político contemporáneo.jdgar.92@gmail.com 


\section{Speech, silence, and equality of intelligences. Thinking the teaching praxis from a wild pragmatic-realistic view}

\begin{abstract}
The present article proposes to address a recurring problem in the teaching practice: the lack of circulation of speech in the classroom, which is usually accompanied by a widespread apathy among students towards didactic proposals. With the aim of reflecting on this issue, we propose to start from the account of a real case -in our own experience- dealing with this problem, and then we will outline a perspective of analysis of the teaching practice which we call 'wild pragmatic
\end{abstract}

realism'. This will allow us to think about and question this narration of experience in a unique way. Finally, we will relate this perspective with some categories of The Ignorant Schoolmaster by Jaques Rancière so as to question the issue of speech and silence in class.

Keywords. Rancière · speech · equality · impotence-potency
(2) Para un desarrollo de esta idea dialógica en relación con

la enseñanza de la filosofía véase Alejandro Cerletti (2015)

\section{Introducción}

En el presente ensayo nos interesa repensar, a partir de un relato de experiencia propio, un problema posiblemente común a otras experiencias docentes: la apatía, el desinterés, la falta de disposición de los estudiantes para participar y hablar en las clases, cuyo efecto combinado conduce a la escasa circulación de la palabra en el aula. Pensar este problema se vuelve apremiante para aquellos que sostenemos una concepción dialógica en la construcción, circulación y apropiación de los saberes ${ }^{(2)}$.

Mi intención es traer a colación un relato de mi propia práctica personal en una escuela técnica de Santo Tomé (Santa Fe, Argentina), con un 5to año y tomarlo como disparador para la reflexión. Resulta oportuno señalar que tanto la experiencia como el abordaje que vamos a proponer son de carácter particular y no tienen, por tanto, la pretensión de brindar soluciones, alternativas y respuestas generales, sino más bien la intención de exponer ciertas inquietudes y compartirlas, para ver si otros pueden encontrar algún tipo de resonancia en lo aquí planteado.

Entro al aula, saludo y miro. Hoy vinieron casi todos. Igual son pocos. Quince. Comienzo con el tema. Estamos trabajando un texto de Michey Onfray que habla sobre la técnica y el ser humano. La metodología de 
trabajo consiste en hacer una lectura colectiva del texto, cortada con una explicación mía, que intenta rescatar ciertos conceptos centrales. Voy pidiendo que los anoten en sus carpetas, generalmente en forma de esquema conceptual. Me cuesta que los estudiantes intervengan, que hablen. Son muy tranquilos, se "portan bien». Parecen estar siempre cansados. No hablan, no participan. Parecen no estar. Solo se turnan entre dos o tres para ir leyendo. A mis preguntas, generalmente de comprensión, cada tanto sueltan respuestas monosilábicas o interjecciones: «sí», "no», «aja». A veces pienso que siguen las explicaciones, que entienden algo de lo que la planificación supone que deben entender. Otras veces me doy cuenta que efectivamente no. En todo caso, nunca sé con suficiente certeza qué entienden. Qué se llevan de mis clases. Qué efectos produce ¿Hay efectos? ¿Siempre hay efectos?

Empezamos. Pregunto si recuerdan algo. Silencio. Avanzamos en la lectura, pregunto si alguien entendió lo que acabamos de leer. Silencio. Formulo una pregunta sencilla sobre una parte del texto. La tengo que repetir tres veces. Milton finalmente se compadece de mi ridículo: responde a la obviedad de la pregunta. Milton, que en las primeras clases se mostraba activo y revoltoso terminó cediendo al ritmo de los compañeros. Él molestaba a los demás, se paraba, hablaba, rapeaba, pero intervenía, movilizaba algo. A veces creo que prefiero aguantar esa intensidad molesta que la tranquilidad desértica de una clase cuando los otros están pero no están: un sinsentido invade el aula, mi cuerpo, jaquea mi lugar docente, me inmoviliza y dilata al infinito el tiempo.

La crudeza del relato-escena lanza un conjunto de interrogantes:

¿Qué pasa con los jóvenes que asisten a las escuelas y «están en otra», no hablan, no participan? ¿Qué pasa cuando entramos al aula y la disposición a ser parte de la clase no se encuentra en todos los presentes? ¿Qué sucede cuando no necesariamente quienes están, están? ¿Qué hacer con esta suerte de paradoja? Por otra parte, esta pregunta sobre o por el silencio, nos conduce hacia la pregunta por el habla. ¿Qué es, qué significa, entonces, que los estudiantes hablen? Aquí puede ser interesante forzar cierta pregunta tautológica ¿Siempre que el alumno habla, habla? ¿No existe acaso un habla mudo, un habla que en realidad no dice nada? ¿Un habla sin subjetivación? Por el contrario ¿Qué/cómo sería un habla que subjetive? 


\section{Hacia un realismo-pragmático salvaje}

Antes de intentar abordar estos interrogantes quizás sea preciso exponer desde dónde nos gustaría pensarlos. En este sentido, nos interesa proponer una perspectiva de análisis que podríamos denominar realismo-pragmático salvaje. Se trata, antes que de un modo de enunciación, de un modo de percepción, o mejor dicho, de un modo de disponerse para percibir y luego poder analizar, pensar y actuar. Este modo de disponerse nos permite rápidamente alejarnos de ciertas narrativas teóricas de la didáctica, críticas o no, que consideramos, idealizan de diversos modos la praxis docente, al presuponer (o proponer) figuras, roles, misiones o mandatos a priori, que confían desde el vamos en la existencia (o en la posibilidad de restaurar) un dispositivo institucional y una práctica que como tal, al menos en la experiencia del relato, no existe o no funciona. La suspensión y rechazo a cierta idea o imagen a priori de la Escuela y sus distribuciones y roles, a cierta visión «bella» de la praxis docente como emancipadora, no es porque tengamos a mano una mejor visión de cómo son o deben ser las cosas, sino porque creemos que estas imágenes lejos de ser operativas, obstaculizan posibles pensamientos y respuestas más eficaces en algunas situaciones concretas, como la aquí propuesta.

Esta disposición para la percepción es realista y pragmática porque parte de lo que hay y se pregunta por las formas de afectarlo (qué funciona, qué produce efectos). Su pragmatismo busca una eficacia específica; no un juicio general y definitivo de cómo deben ser las cosas, sino una acción que busque transformar un estado específico de impotencia por uno de mayor potencia. Para ello quizás sea preciso, en primer lugar, habitar lo disruptivo: desterrar ciertas imágenes y ciertos lenguajes pedagógicos ya tradicionales y suspender ciertas convenciones de las que docentes y estudiantes somos partes y estamos habituados. Es salvaje, justamente, porque para analizar y revisar la propia práctica, precisa correrse del «rol social» del docente, rechazar el "contrato social-pedagógico», para aprender una percepción atenta a los modos en que lo «no-escolar» (Duschatzky y Sztulwark, 2011) se cuela en las instituciones, a fin de poder tomar decisiones a-morales (decisiones pedagógicas que no tengan como criterio algo más allá del aquí ahora de la práctica). 
Esta propuesta encuentra su anclaje en dos preceptos que pueden ser oportunos para pensar en clave pedagógica. El primero de ellos es de Spinoza, quien al inicio del Tratado Político señala, que hay que partir de concebir a los hombres tal cual son y no como pretendemos que sean, si es que queremos plantear algo serio en el orden práctico. (Spinoza, 2014:341) El segundo es del músico Carlos Solari en torno a la escucha: «Escuchar a los pibes y pibas porque en sus nervios hay muchas más información del futuro que las que alguien como yo puede brindar»(3). Ambas se acercan quizás a ciertos planteos actuales de Silvia Duschatzky (2017) en torno a la escucha en la escuela. Creemos que esta disposición nos permite situarnos en las condiciones concretas a partir de las cuales tenemos que pensar, revisar e inventar en relación a nuestras prácticas. Su realismo no es cínico o conformista, no implica hacer coincidir lo posible con lo real, sino partir de lo real para ver las posibilidades específicas de afectar esta práctica.

Desde esta perspectiva podemos hacer torcer la escena del relato propuesto. Podemos desplazarnos de ciertos supuestos que allí el narrador pone en juego y la escena puede ser interrogada y leída de otra manera. En primer lugar, desde este realismo, podríamos plantear que la apatía y el silencio de los estudiantes aparece como condición de nuestra práctica y no como algo que falta, algo que estaría funcionando mal del dispositivo institucional, algo que debería darse y no se da. Algo, por tanto, de que lamentarnos. En este sentido, esta perspectiva nos corre de entrada de la victimización propia y la posibilidad de caer en discursos de la impotencia: «Ya no hay tiempo de lamentos». Este realismo nos desvía así del círculo de la impotencia propio del eterno lamento de aquello que "debería darse y no se da" y se abre la pregunta en torno a qué se puede hacer, cuando, por ejemplo, el silencio y la apatía constituyen el punto de partida, la premisa, de la praxis áulica. En segundo lugar, lo salvaje nos permite ir más allá y poner entre paréntesis cierta imagen tradicional que supone y nos dice que cuando entramos al aula hay alumnos, y más aún, que estos van a escuchar y participar activamente. Pensar sin este a priori del dispositivo institucional que prefigura cierta regulación de los roles y acciones en el aula, quizás nos da más herramientas, más estrategias pedagógicas para nuestra praxis. Tercer desplazamiento, lo pragmático que toma como punto de partida la premisa de que cuando
(3) La cita pertenece a la emblemática «Conferencia de Olavarría» brindada por la banda el is de agosto de 1997 tras la suspensión de un recital previsto para el día siguiente en esa localidad. 
entramos al aula los estudiantes no siempre van a estar y que su atención si es que se da será fluctuante, nos permite diseñar otro tipo de estrategias y propuestas que busquen una eficacia especifica. Otra vez, no lamentar y ver qué se puede activar. Ni ingenuidad ni quietismo.

\section{Mutismo, pereza e igualdad de las inteligencias}

Creemos que este realismo-pragmático salvaje nos permite investigar positivamente la materialidad del aula. En el caso de la escena propuesta nos interpela a hacer el esfuerzo por percibir y pensar sin un diagnóstico previo qué expresan este silencio, este desinterés y esta apatía de los estudiantes. Se trata de un intento por suspender y aplazar el juicio en torno a qué significan, para disponerse primero en una posición de escucha. En este sentido, esta perspectiva requiere el ejercicio de cierta ignorancia. Una ignorancia que implica poder ir abiertos, sin cifrar del todo y a priori las contingencias de las distintas situaciones escolares, permitiendo así experienciar/experimentar la materialidad del aula. Habilita otra percepción de lo que acontece; quizás permite una escucha menos prefigurada y más vital-material de lo que pasa en el aula. Por esto, entendemos que esta perspectiva -que practica cierta ignorancia- puede aliarse para ayudarnos a leer la escena inicial, con ese texto-experiencia de Jacques Rancière titulado El maestro ignorante (2007). Aquí se abren nuevos interrogantes ¿Cómo pensar el problema del silencio desde la hipótesis de Jacotot y desde la idea de palabra que aparece en EI maestro ignorante? ¿Qué pasa con la igualdad de las inteligencias cuando la apatía, el desinterés y la impotencia se apoderan del aula?

En este texto, Rancière, retomando la aventura intelectual de Joseph Jacotot, propone el axioma de la igualdad de las inteligencias: «Todas las inteligencias son iguales, todos los hombres pueden lo que puede un hombre». Hipótesis que no pretende tener un estatus científico (ni biológico, sociológico o psicológico) sino que es un producto político de la imaginación radical (Tatián, 2012:8). La igualdad de las inteligencias no es una Verdad, sino una apuesta práctica a verificar en cualquier situación. Para Jacotot la opinión de la igualdad de las inteligencias es el «sentimiento de que uno puede lo 
que pueden los otros en la exacta medida en que los otros pueden lo que uno puede». (Rancière, 2019:61) La voz del maestro ignorante nos aclara que «Nuestro problema no consiste en probar que todas las inteligencias son iguales, sino en ver qué se puede hacer a partir de esa suposición» (Rancière, 2007:66).

Para Jacotot usar la propia inteligencia no es más que ponerla en movimiento. Si bien todos tenemos la misma inteligencia, todos somos capaces y participamos de una potencia común, no todos la usamos de la misma manera. Según él, la comprensión y el aprendizaje no son solo una cuestión de inteligencia, sino ante todo de voluntad. De allí su segunda tesis importante: «el hombre es una inteligencia al servicio de una voluntad». (Rancière, 2007) Voluntad(4) e inteligencia son las dos facultades que todo animal razonable, todo ser de palabra, tiene. Mientras que la inteligencia, según el axioma práctico de la igualdad, se encuentra en todo individuo, la voluntad es de naturaleza fluctuante, difusa y variable. Para Jacotot/ Rancière la voluntad varía de acuerdo a los intereses, necesidades y circunstancias siempre contingentes que empujan o no a los hombres a poner en movimiento su inteligencia. (Rancière, 2007:72) Esta oscilación de las voluntades explicaría por qué a partir de la igualdad de las inteligencias, sus manifestaciones, no obstante, pueden ser diferentes. La emancipación intelectual no es otra cosa que la conciencia del axioma igualitario y su puesta en práctica, su verificación a través de los efectos materiales que produce el encuentro entre inteligencia y voluntad en el ser hablante. Jacotot llama atención a este encuentro, en el cual la inteligencia se somete a una voluntad activa y en búsqueda. Por el contrario, cuando la voluntad se retira, se diluye y su fuerza e intensidad disminuye, estamos ante la desatención, distracción o lo que Jacotot llama pereza. (Rancière, 2007:77)

La palabra en el planteo de Jacotot cobra un rol central. La verificación de la hipótesis de la igualdad de las inteligencias «requiere que se empiece a hablar» (Rancière, 2007:40). El maestro ignorante es aquel que organiza su práctica bajo la premisa de la igualdad de los seres parlantes. Es aquel que pone un objeto como vínculo común entre los seres (libro, contenido, recurso) e interroga, no como sabio o maestro a alumnos, sino como los hombres y mujeres interrogan a otros hombres/mujeres. «¿Qué ves? ¿Qué
(4) La voluntad no es pensada por Rancière tanto como el poder de decisión que surge de un sujeto autocentrado, sino como la constancia de un trabajo de experimentación que desplaza los límites consensuales (policiales) de lo que es posible pensar, decir $y$ hacer por los sujetos. 
piensas? ¿Qué haces?» El elemento en común o «contenido» no es tanto un saber a adquirir, sino a com-partir (partage) para despertar una voluntad perezosa, para mantener encendida la atención y demandar la palabra atenta del otro. La emancipación intelectual necesita que el sujeto empiece a hablar de modo atento usando la propia inteligencia, es decir, sometiéndola a la propia voluntad.

Volvamos a nuestra escena. Los aportes de Rancière nos llevan inmediatamente a pensar entonces el mutismo y la indiferencia de los estudiantes en términos de pereza o desatención; una ausencia de movimiento de la voluntad que no desea implicar su inteligencia. En efecto, en la escena de nuestro relato prima la pereza, ahora bien es posible abrir la pregunta ¿Pereza de quién? ¿Solo de los estudiantes?

En las salas docentes, lugar habitual de lamento e impotencia, muchas veces la respuesta es tan clara como a-problemática: «a los chicos no les interesa nada». La culpa inmediatamente se exilia a ellos, a los padres, al sistema escolar, a la sociedad actual, etc. Desde la perspectiva propuesta, no interesa sostener si estos juicios son verdaderos o falsos, sino marcar que sus efectos no dejan de ser paralizantes. Nos dejan quietos. ¿De qué nos sirve tener una verdad que nos condena a la impotencia? Prestar atención a lo que sucede y circula en las salas docentes (en términos de discursos, gestos corporales, frases recurrentes, malestares, juicios valorativos, etc.) pone inmediatamente en evidencia que la pereza no es solo de los estudiantes, sino que esta se relaciona con una más profunda y más general: la pereza de la institución escolar y de nosotros mismos para re-pensar y revisar la desconexión entre el deseo/interés de los estudiantes (que muchas veces ignoramos), nuestra propuesta (cuyo valor generalmente afirmamos dogmáticamente) y el sentido de la escuela (que muchas veces damos por obvio, sin repensarlo). (Creciendo Juntos / Colectivo Situaciones, 2008:66) Una revisión posible de la propia práctica, en relación con el problema de la falta de circulación de la palabra, podría justamente empezar por interrogarnos en torno a los modos en que exigimos o pedimos la palabra, a los modos en que preguntamos en las clases. En la escena propuesta, mis preguntas hacia los estudiantes se dirigían a saber si se había comprendido lo recientemente leído, con lo cual se exigía una respuesta capaz de 
reproducir, quizás con otras palabras, lo mismo que ya había sido dicho unos minutos antes. Este modo de pedir la palabra limita el habla del otro a meramente reproducir lo ya dicho. Este modo de preguntar es analogable a lo que Rancière/Jacotot Ilama "preguntas socráticas» y califica como «embrutecedoras». (2007:47) Para Jacotot, la mayéutica de Sócrates es el método explicador por excelencia porque se trata de un modo de preguntar cuyo camino hacia el saber coincide con la constatación de la incapacidad del interrogado para arribar a él por su cuenta. a. Lo que aquí llamaremos «procedimiento socrático» consiste en guiar al estudiante mediante preguntas destinadas a una respuesta unívoca, la cual el docente ya tiene y finge no saber. Aquí los caminos del saber y del habla exigida están marcados de antemano por la planificación y/o el pensamiento del docente, que mediante preguntas buscan guiar la palabra del otro. El modo «socrático» de interrogar exige una respuesta que el docente ya sabe de ante mano, y en este sentido, busca la palabra anunciada y previsible. Por ello, cierra las respuestas alternativas, aquellas que obliguen al otro a trazar su singularidad a poner realmente en movimiento su inteligencia. Jacotot nos advierte quizás de algo interesante: cuando el docente conoce las respuestas o pregunta esperando una respuesta específica, se corre el riesgo de que él dirija la inteligencia del estudiante a hacer contestar lo que él espera, o que el estudiante someta su inteligencia y palabra a lo esperado por el docente, lo que no deja de ser un modo de enseñar bajo la lógica explicadora, cuyo resultado nunca es la emancipación intelectual, sino el embrutecimiento del otro. El otro no aprende a poner en movimiento su propia inteligencia, sino a someterla a la del maestro explicador. En este sentido, también podemos decir que este habla exigido por la pregunta socrática es una forma de mutismo. El estudiante en caso de hablar es hablado por la planificación o por la respuesta que el docente tiene guardada y finge no saber. Su habla no es más que una reproducción de lo esperado, que no exige necesariamente un compromiso activo de su inteligencia y menos aún es un habla capaz de transformar al sujeto que lo enuncia.

Pero a la vez, revisar los modos "socráticos» de preguntar, nos permite conjeturar que este modo de interpelar puede producir en los estudiantes el efecto contrario al pretendido; lejos de lograr que hablen, pareciera que 
cuando la preguntas están dirigidas a una «buena» y única respuesta, los estudiantes calculan más la respuesta que van a dar; saben que si responden de modo incorrecto el docente paternalmente va a hacerles saber y exponer ante los demás su ignorancia y luego guiarlos hacia la respuesta correcta, lo cual tiene como efecto que muchas veces opten por quedarse en silencio. Lejos de abrir la pregunta por lo que pueden las inteligencias en movimiento, estas maneras de preguntar pueden obturar cualquier palabra propia de los estudiantes o conducirlos al silencio por «no saber» la respuesta exacta que el docente espera.

\section{A modo de conclusión: habla muda y habla excesiva}

En El maestro ignorante, Rancière, nos impulsa a pensar que tanto el habla como la escucha son esfuerzos de «traducción» y «contra traducción» que las voluntades implicadas deben llevar a cabo. Para Jacotot, la arbitrariedad de todo lenguaje reúne en la distancia, en el sentido de que obliga a los seres hablantes a comprenderse (traducirse) para poder comunicarse, a la vez que esa distancia, basada en la contingencia de la comprensión de lo que el otro dice, funda una comunidad de las inteligencias, entre los seres capaces de traducirse unos a los otros (Rancière, 2007:80). En este sentido, podríamos asociar el mutismo a la falta de voluntad tanto para expresar (traducir) lo que se ve y se piensa en la materialidad del habla, así como la ausencia de voluntad en contra de traducir o adivinar los pensamientos expresados por los otros, de reapropiárselos uno mismo.

Por otro lado, los aportes de Rancière nos llevan a pensar que toda clase bajo la lógica explicadora constituye cierto reparto de lo sensible, cierta estructuración del espacio áulico en términos de lugares, funciones y capacidades de habla que se caracteriza por la exclusión de todo suplemento, de todo exceso no previamente contado. El docente explicador ha planificado, sabe los objetivos, los tiempos y cómo guiar a los alumnos hacia el camino del saber (métodos). Sabe qué palabra cuenta para ello y cuál no, cuándo los alumnos deben hablar y cuándo no. A contrapunto, la emancipación intelectual precisa que se den momentos de habla excesivos, implanificables 
e intempestivos. Que emerja e irrumpa aquella palabra que corta el tiempo de la clase y que verifica la potencia de cualquiera a hablar de manera atenta. Este «habla excesivo» interrumpe, modifica y altera aunque sea un mínimo el orden de la clase planificada. Produce un desplazamiento que reconfigura el orden de lo que era pensable, decible y esperable en la clase. No implica meramente que los alumnos hablen cuando su palabra no es exigida, ni que hablen demasiado, sino que su potencia es la «traducción» singular que opera entre lo que fue puesto en común y las relaciones novedosas que es capaz de producir la palabra atenta dicha por cualquiera. Esta palabra atenta que produce una alteración en el paisaje de lo que era esperable que pase en una clase, que re-ordena ese orden de lo planificado, lo previsto y sus relaciones, no es otra cosa que la verificación de la igualdad de las inteligencias, la afirmación de los individuos como fuerzas productivas de pensamiento capaces de pensar nuevos vínculos en relación con lo que fue puesto en común. Y esa palabra excesiva, ese desacato dado por cualquiera, es a la vez la re-apertura práctica de la pregunta más importante de la enseñanza: ¿Quién puede pensar?

\section{Referencias bibliográficas}

Cerletti, A. (2015). Didáctica filosófica, didáctica aleatoria de la filosofía Educação. Revista do Centro de Educação, Universidade Federal de Santa Maria, RS, Brasil vol. 40 (1, enero-abril), pp. 27-36.

Creciendo Juntos/Colectivo situaciones (2008). Un elefante en la escuela. Pibes y maestros del conurbano. Buenos Aires: Tinta de Limón ediciones.

Duschatzky, S. (2017). Política de la escucha en la escuela. Buenos Aires: Editorial Paidós.
Duschatzky. S. y Sztulwark. D. (2011). Imágenes de Io no escolar. Buenos Aires: Paidós.

Spinoza, B. (2014). Tratado teológico-político. Tratado político. Madrid: Gredos.

Rancière J. (2007). El maestro ignorante. Tr Claudia Fagaburu. Buenos Aires: El Zorzal Ediciones.

Rancière, J. y Bassas, J. (2019). El litigio de las palabras. Diálogo sobre política del lenguaje. Barelona: Ned Ediciones.

Tatián, D. (2012). Lo impropio. Buenos Aires: Editorial Excursiones. 